\title{
Pattern of mammographic findings in Sokoto, Nigeria
}

\author{
M. Danfulani'1, Sa'idu S. Ahmed', Ma'aji S. Mohammed'1, Musa M. Awwal² \\ ${ }^{1}$ Department of Radiology Usmanu Danfodiyo University Teaching Hospital, Sokoto, ${ }^{2}$ Department of Anatomy, College of Health Sciences, \\ Usmanu Danfodiyo University, Sokoto
}

\section{A B S T R A C T}

Background: Radiological examination of the breast is established as an essential part of the modern multidisplinary approach to effective investigation and management of breast diseases. The standard techniques used for breast imaging are screen film X-ray mammography and real time ultrasound. The aim of this study is to document mammographic findings in females seeking medical attention at the Usmanu Danfodiyo University Teaching Hospital Sokoto, Nigeria. Methods: The study was a descriptive retrospective analysis of the mammographic breast examinations (both screening and diagnostic) seen over a period of one year (February 2012 - January 2013). A total 125 patients were recruited in this study. Relevant parameters extracted from the records included patients age, presenting complain, referring clinic/unit, indications and the reporting radiologist findings (diagnosis). All the data collected were analyzed using a Statistical Package for Social Sciences (SPSS) version 17.0 windows. Results: The age range of the study participants was 18 to 71 years with a mean and standard deviation value of $41.87 \pm 10.15$. Majority of our patients (44\%) were referred from GOPD (General Out Patient Department); followed by SOPD (Surgical Out Patient Department) with 41 patients (32.8\%). Other referring clinics included Accident and Emergency (A and E) (3.2\%), Staff Clinic (1.6\%), Medical outpatient Department (MOPD) 4.0\%, Clinic 1 less than 1\%. Gynea Clinic (3.2\%) and Radiotherapy Unit (1.6\%). The commonest indications for these examinations in our patients include Breast Pain (unilateral or bilateral); Breast Lump (unilateral or bilateral), bloody nipple discharge, ?Breast Cancer (left or right), Fibrocystic dysplasia, mastitis among others. The predominant diagnosis observed in our results was BIRADS 1 (normal examination) which constituted 73 (58.4) patients. Conclusion: Most of our patients for diagnostic mammography were found to have Benign breast diseases than breast cancers; suggesting that there is a high diagnostic yield of mammography in the evaluation and management of breast diseases in this environment.

Key words: Mammographic findings, Benign breast diseases, Females

\section{INTRODUCTION}

Mammography is a radiological imaging modality that uses low energy radiation (soft tissue radiation) to establish a diagnosis of palpable and non palpable breast lesions. It may either be for the purpose of screening ${ }^{1-3}$ or diagnosis. ${ }^{4}$ Over the years, mammographic appearance of the breast have received widespread interest especially as a marker for the risk of breast cancer. ${ }^{5-9}$

Radiological examination of the breast is established as an essential part of modern multidisciplinary approach to effective investigation and management of breast diseases. ${ }^{1}$
Access this article online

Website:

http://nepjol.info/index.php/AJMS
The standard techniques used for breast imaging are screen film X-Ray mammography and real - time ultrasound. ${ }^{1}$ Other newer techniques include MRI, Colour Dopler and Contrast ultrasound, scintimammography and digital mammography. ${ }^{1}$

The radiologist has a central role in management of breast diseases and should have use of all facilities to ensure accurate diagnosis including mammography, ultrasound and Biopsy/localization techniques. ${ }^{10}$

The mammographic appearance of the breast has received widespread interest over recent years as a marker of risk 
for breast cancer. The relative proportion of radiolucent fat and radio dense connective tissue and glandular epithelium within the breast gives rise to variations in appearance of the breast as seen on mammograms. ${ }^{11,12}$

The aim of this study is to document the mammographic findings in females seen at the Usmanu Danfodiyo University Teaching Hospital (UDUTH), Sokoto, Nigeria.

\section{MATERIALS AND METHODS}

The study was a descriptive retrospective analysis of the mammographic breast Examinations (both screening and diagnostic) seen over a period of one year (February 2012 to January 2013).

Records of all the patients that came in for mammography since the installation of the equipment were retrieved from records unit of the radiology department of Usmanu Danfodiyo University Teaching Hospital (UDUTH) Sokoto. The examination was done with a Mammography machine Model (The Senograph DMR ${ }^{\mathrm{T}}$ mammographic units).

A minimum of at least two views were taken Mediolateral (MLV) and Cranio - Caudal (CC); Except where there was need for a modified additional view which was appropriately taken. Relevant parameters extracted from the records included patients age, presenting complain, referring clinic/unit, indications and the reporting radiologist finding (diagnosis). All the data collected were entered into Microsoft Excel and analyzed using SPSS version 17.0 Windows.

\section{RESULTS}

The age range of the study participants was 18 to 71 years with a mean and standard deviation value of $41.87 \pm 10.15$. Majority of our patients (44\%) were referred from GOPD (General Out Patient Department); followed by SOPD (Surgical Out Patient Department) with 41 patients (32.8\%). Other referring clinics included Accident and Emergency (A and E) (3.2\%), Staff Clinic (1.6\%), Medical outpatient Department (MOPD) 4.0\%, Clinic 1 less than 1\%. Gynea Clinic (3.2\%) and Radiotherapy Unit (1.6\%) (Table 1).

Majority (39.2\%) of the patients were aged between 36-45 years. The least affected age groups were those between 66-75 years. Patients aged 40 years had the highest presentation as shown in Table 2.

The commonest indications for these examinations in our patients include Breast Pain (unilateral or bilateral); Breast Lump (unilateral or bilateral), bloody nipple discharge,

\begin{tabular}{lcc}
$\begin{array}{l}\text { Table 1: Distribution of patients referred from } \\
\text { various clinics }\end{array}$ & Prequency & Percentage (\%) \\
\hline Referring clinics & 55 & 44.0 \\
\hline GOPD & 41 & 32.8 \\
SOPD & 8 & 6.4 \\
RTC & 5 & 4.0 \\
MOPD & 4 & 3.2 \\
GYNEA & 4 & 3.2 \\
A/E & 2 & 1.6 \\
Staff clinic & 2 & 1.6 \\
Radiotherapy & 1 & 0.8 \\
Urology & 1 & 0.8 \\
Barrack clinic & 1 & 0.8 \\
Clinic 1 & 1 & 0.8 \\
FAW & 125 & 100 \\
Total &
\end{tabular}

GOPD: General outpatient department, SOPD: Surgical outpatient department, RTC: Radiotherapy clinic, MOPD: Medical outpatient department, A/E: Accident and emergency, FAW: Female amenity ward

\begin{tabular}{|lcc|}
\hline \multicolumn{3}{|c}{ Table 2: Age group range of subjects in this study } \\
\hline Age range (years) & Frequency & Percentage (\%) \\
\hline $15-25$ & 7 & 5.6 \\
$26-35$ & 26 & 20.8 \\
$36-45$ & 49 & 39.2 \\
$46-55$ & 31 & 24.8 \\
$56-65$ & 11 & 8.8 \\
$66-75$ & 1 & 0.8 \\
Total & 125 & 100 \\
\hline
\end{tabular}

?Breast Cancer (left or right), Fibrocystic dysplasia, mastitis among others. The predominant diagnosis observed in our results was BIRADS 1 (normal examination) which constituted 73 (58.4) patients.

As shown in Table 3 above, $21.6 \%$ of all the patients came for Routine Examination (Screening mammography) the remaining patients constituted diagnostic mammography. The predominant diagnosis observed in our results was birads 1 (normal Examination) which constituted about 73 patients (58.4\%). Other diagnosis (Breast Pathologies) encountered include: Benign Breast lesions like Fibroadenoma, Fiboadenosis, Traumatic Fat necrosis, intramammary hymphadenopathy, Benign breast calcifications and breast carcinoma among others. Table 4 shows the pattern of the disease encounter in these studies. Benign Breast disease was commonly seen in this study than malignancy.

\section{DISCUSSIONS}

High quality mammography screening is a major health achievement as it reveals various types of breast lesions including cancers. ${ }^{13}$

All the patients in this study were women with a mean age of $41.87 \pm 10.15$. Majority of the patients (44\%) were 


\begin{tabular}{lcc} 
Table 3: Frequency table for indications of the \\
examinations & Frequency & Percentage (\%) \\
\hline Indication & 27 & 21.6 \\
\hline Routine & 12 & 9.6 \\
Pain - bilateral & 13 & 10.4 \\
Lt breast & $\mathrm{NIL}$ & 0 \\
Rt breast & 10 & 8 \\
Lump - bilateral & 13 & 10.4 \\
Lt breast & 9 & 7.2 \\
Rt breast & 2 & 1.6 \\
Pain and Lump - bilateral & $\mathrm{NIL}$ & 0 \\
Lt breast & 1 & 0.8 \\
Rt breast & 3 & 2.4 \\
Chronic mastitis & 1 & 0.8 \\
Mastitis R/O breast Ca & 2 & 1.6 \\
Fibrocystic dysplasia of both breast & 4 & 3.2 \\
Fibro adenoma & 1 & 1.6 \\
Retracted nipple with abscess & 5 & 4 \\
RightAxillary hymphoderapthy & 7 & 5.6 \\
Ca Breast & 8 & 6.4 \\
Ca (Lt) breast & 3 & 2.4 \\
Ca (Rt) breast & 4 & 3.2 \\
Others & 125 & 100 \\
Total & & \\
\hline
\end{tabular}

\begin{tabular}{lcc} 
Table 4: Pattern of diagnosis among the study \\
participants & \multicolumn{3}{l}{ Frequency } & Percentage (\%) \\
\hline Diagnosis & 73 & 58.4 \\
\hline BIRADS 1 Normal examination & 22 & 17.6 \\
BIRADS 0 breast uss suggested & 8 & 6.4 \\
BIRADS 2 (benign breast lesion), & 4 & 3.2 \\
BIRADS 3 (Benign lesion), & & \\
Uss suggested & 3 & 2.2 \\
BIRADS 3 breast uss suggested & 3 & 2.2 \\
BIRADS 4, biopsy and histology is & & \\
advised & 2 & 1.6 \\
BIRAD 4, Biopsy is Suggested & 2 & 1.6 \\
Compression view suggested & 1 & 0.8 \\
Features suggest reoccurrence on & & \\
the right breast & 1 & 0.8 \\
$\begin{array}{l}\text { Possible metastasis for the left } \\
\text { Fibroadenoma with cystic }\end{array}$ & 1 & 0.8 \\
degeneration & & \\
Biopsy is suggested for mass for & 1 & 0.8 \\
further evaluation & & \\
Malignant lesion biopsy is advised & 1 & 0.8 \\
Bilateral axillay masses & 1 & 0.8 \\
BIRADS 3 & 1 & 0.8 \\
Bilaterally dense breast making & 1 & 0.8 \\
lesion to be easily mark, BIRADS 0 & & \\
Biopsy and Uss suggested for & 1 & 0.8 \\
further evaluation & & \\
Total & 125 & \\
\hline BIRADS: Breast imaging reporting and data system & & \\
\hline
\end{tabular}

referred from GOPD (General Out Patient Department), followed by SOPD (Surgical Out Patient Department) 41 patients $(32.8 \%)$. Other referring clinics included Accident and Emergency (A and E) (3.2\%), Staff Clinic (1.6\%), Medical outpatient Department (MOPD) 4.0\% Clinic 1 less than 1\%. Gynea Clinic (3.2\%) Radiotherapy Unit $(1.6 \%)$.
Majority (39.2\%) of the patients were aged between 36-45 years. The least affected age groups were those between the age ranges of $66-75$ years.

The commonest indications for these examinations in our patients include Breast Pain (unilateral or bilateral); Breast Lump (unilateral or bilateral) bloody nipple discharge? Breast Cancer (left or right), Fibrocystic dysplasia, mastitis among others. This also agrees with findings with similar reports ${ }^{13,14}$ where breast lumps and pains in either or both breasts constituted the largest presenting symptoms among patients. This may not be unassociated to race, geographical location and similar cultural practices.

Out of the total 125 participants, $21 \%$ of all the patients came for routine examination (screening mammography) while the remaining $79 \%$ constituted diagnostic mammography. This may be due to lack of awareness with regards the importance of screening mammography among our patients. This observation does not agree with previous studies ${ }^{13,14}$ where majority of the study participants came for diagnostic mammography rather than screening.

The predominant diagnosis observed in our results was birads 1 (normal examination) which constituted about 73 patients (58.4\%). Other diagnosis (Breast Pathologies) encountered include: Benign Breast lesions like Fibroadenoma, Fiboadenosis, Traumatic Fat necrosis, intramammary hymphadenopathy, Benign breast calcifications and breast carcinoma among others.

Breast lesions especially malignant ones are demonstrated mammographically mainly as density ${ }^{15}$ or microcalcifications. ${ }^{16,17}$ Using observed mammographic appearances, the breast can be considered as being composed on one hand of connective tissue stroma and glandular tissue on the other hand. ${ }^{16,17}$ This results in varying areas of opacities and lucencies on mammographic image. . $^{16,17}$

This study showed that most of the women imaged were in the 36-45 years age group (39.2\%) and less than 10\% were aged 56 years and above reiterating the age group of women who do mammography elsewhere ${ }^{18,19}$ and in Nigeria. ${ }^{13,20}$ Similarly, the age group with the highest frequency of mammographic examination was 40-49 as reported by Kiguli et al., ${ }^{21}$ and Ohlinger et al. ${ }^{22}$ in Uganda and Germany respectively. This does not agree with our findings presumable due to geographical location and perhaps the level of awareness.

Mammographic evaluation of the breast remains the only single modality that had been proven by clinical trials to 
reduce breast Cancer mortality. ${ }^{23}$ However in the overall evaluation of a mammogram the prevailing breast density is an important observation since breast density has been implicated in breast Cancer occurrence. ${ }^{23}$

All the patients are women coming in either for screening or diagnostic mammography, no single referral is a man this is similar to a pattern seen locally elsewhere in South-Western Nigeria. ${ }^{13,20}$

The referring clinics were widespread with majority of our patients from GOPD and SOPD confirming the increasing level of awareness of mammography in the evaluation of breast diseases. Most of our patients are symptomatic confirming the fact that majority of our patients are for diagnostic mammography. The referring pattern noted in the study is similar to what was observed in local study cited above. $^{20}$

The commonest indication for the examination amongst the patients is routine (screening mammography) which constituted about $21.6 \%$, the remaining are referred with symptoms for diagnostic purpose. Of the diagnostic group the commonest indication for mammography is pain $(20 \%)$ with pain in the left breast commoner, lump (25.6\%) the left breast commoner and combination of pain and lump (2.4\%). Others are Fibroadenoma (3.2\%), chronic mastitis $(3.2 \%)$ and malignancy $(14.4 \%)$. This pattern of presentation is similar to what was seen in a study done in Lagos (South-Western Nigeria). ${ }^{21}$ Benign breast diseases is the commonest finding in this study. This is in conformity to what as seen locally. ${ }^{21}$

Benign breast diseases is the commonest finding in this study than malignant lesions; very few our patients fall in to the category of BIRADS 3 and above; these patients need to be further evaluated with specific interval repeat mammography and Biopsy for definitive confirmation of malignancy.

\section{CONCLUSION}

Although majority of our patients came for diagnostic mammography; there is increasing trends for routine screening mammography; most probably from increased awareness of its role in early detection of breast cancers.

Most of our patients for diagnostic mammography were found to have Benign breast diseases than breast cancers; suggesting that there is a high diagnostic yield of mammography in the evaluation and management of breast diseases in this environment. About $17 \%$ of all the examination was inconclusive suggesting the fact that mammography alone is not enough in the evaluation of breast diseases and most often must be complimented with other imaging modalities like ultrasonography, and magnetic resource imaging (MRI).

\section{REFERENCES}

1. Smat CR, Hendrick RE, Rutledge JH and Smith RS. Benefit of mammography screening in women ages $40-49$ years. Current evidence from randomized controlled trials. Cancer 1995; 75 : 1619-1626.

2. Taber L, Chen HH, Fagerberg G, Duffy SW and Smith TC. Recent results from the Swedish two - country Trial: The affects of age, histologic type, and mode of detection on the efficacy of breast Cancer Screening, J Natl Cancer Inst Monogr 1997; 43-47.

3. Tabar L, Fagerberg G, Duffy SW, Day NE, Gad A and Grontoft $O$. Update of the Swidish two - country program of mammographic screening for breast cancer. Radio Clin North Am 1992; 30:187-201.

4. Lee $\mathrm{CH}$, Smith RC, Levine JA, Troiano RN and Tocino I. Clinical usefulness of MR Imaging of the breast in the evaluation of the problematic mammogram. AJR 1999; 173: 1323-1329.

5. Wolfe JN. Breast patterns as an index of risk for developing breast cancer. AJR 1976; 126: 1130-1139.

6. Gapstur SM, Lopez P, Colangelo LA, Wolfmann J, Van Horn $L$ and Hendrick RE. Association of Breast Cancer in Hispanic Women. Cancer Epidemiol. Biomakers and Prevention 2003; 12: 1074-1080.

7. Boyd NF, Gillian SD, Stone J, Gunasekara A, Dallas English R, Margaret RE, et al. Heritability of mammographic Density, a risk factor for breast Cancer. The N Engl J Med 2002; 347: 886-894.

8. Witt I, Hassan HS and Brunner S. The risk of developing breast cancer in relation to mammography findings. Euro $\mathrm{J}$ Radiol 1984; 4(4): 65-67.

9. Byrne C, Schairer C, Wolfe J, Parekh N, Salane M, Brnton LA, et al. Maammographic features and breast cancer risk: effects with time, age and menopausal status. J Natl Cancer Inst 1995; 87: 1622-1629.

10. Henson DE, Chu KC and Levine PH. Histologic grade, stage and survival in breast cacinoma: comparism of African, American and Caucasian women, Cancer 2003; 98: 908-917.

11. Newman LA, Mason J, Cote D, Vin Y, Carolin K, Bouwman D, et al. African-American ethnicity, socioeconomic status, and breast cancer survival: A meta-analysis of 14 studies involving over 10,000 African-American and 40,000 White American patients with carcinoma of the breast. Cancer 2002; 94:2844-2854.

12. Oza AM and Boyd NF. Mammography Parenchymal patterns: a marker of breast cancer risk. Epidemiol Rev 1993; 15: 196-208.

13. Akinola RA, Akinola OL, Shittu L, Balogun BO, and Tayo AO. Appraisal of mammography in Nigerian Women in a new Teaching Hospital. Scientific Research and Essay 2007; 2(8): 325-329.

14. Awosanya GO, Jeje EA, Bayagbona D and Inem VA. Screening and diagnostic mammographic findings of 115 consecutive Nigerian women; A 2 year study inj a city pricate hospital. Nig Qt Hosp Med 2004; 14: 166-168.

15. Kopans DB. Breast Imaging. Lippincott - Raven Publishers, Philadelphia 1998.

16. Tabar $L$ and Dean PB. Teaching Atlas of Mammography. Georg Thiemi Verlag, Stuttgard 1983.

17. Lanay M. Diagnosis and differential diagnosis of breast calcification. Springer-verlag, Berlin 1986.

18. Barlow WE, Lehman CD, Zheng $\mathrm{Y}$, Ballard-Barbash $\mathrm{R}$, Yankaskas BC, Cutter GR, et al. Performance of diagnostic 
mammography for women with signs or symptoms of breast cancer. J Natl Cancer Inst 2002; 94:1151-1159.

19. Sala E, Warren R, McCann J, Duffy S, Luben R and Day NE. High-risk mammographic patterns and anthropometric measures: a case-control study. Br J Cancer 1999; 81: 1257-1261.

20. Adeyomoye AAO, Awosanya GOG, Adesanya AA, Anunobi CC and Osibogun A. Medical Audit of Diagnostic Mammographic Examination at the Lagos University Teaching Hospital (LUTH) Nigeria, The Nigerian Postgraduate Medical Journal, 2009; 16(1): $25-29$.
21. Kiguli NE, Mubuuke AG, Businge F, Kawooya GM, Nakatudde R, Byanyima KR, et al. Current Knowledge, Attitude and Practices of women on breast cancer and mammography at Mulago hospital. Pan Afr Med Journal 2010; 5: 9-21.

22. Ohlinger R, Heyer H, Thomas A, Paepke S, Warm H, Klug U, et al. Non-palpable breast lesions in initial ultrasonography and comparison with mammography. Anticancer Research 2006; 26 : 3943-3956.

23. Tabar L. and Gad A. Screening for breast cancer, the Swedish trial Radiology 1981; 138: 219-222.

\section{Authors Contribution:}

DM - Concept and Study Design, Analysis of Data, Interpretation and Manuscript preparation. SSA - Study Design and Manuscript preparation. MSM - Study Design and Critical revision of manuscript. MMA - Analysis of Data, Literature Search and Manuscript preparation.

Source of Support: Nil, Conflict of Interest: None declared. 